\title{
Effect of Relative Humidity and Interrupted Wetness Periods on Brown Spot Severity of Pear Caused by Stemphylium vesicarium
}

\author{
I. Llorente and E. Montesinos
}

Institute of Food and Agricultural Technology-CeRTA, University of Girona, Avda. Lluis Santalo, s/n, 17071 Girona, Spain. Accepted for publication 28 September 2001.

\begin{abstract}
Llorente, I., and Montesinos, E. 2002. Effect of relative humidity and interrupted wetness periods on brown spot severity of pear caused by Stemphylium vesicarium. Phytopathology 92:99-104.

Field observations in four pear orchards during 5 years from April to October indicated that days with uninterrupted wetness of variable length represented $83.9 \%$ of the total days studied. However, days with surface wetness interruptions and with high relative humidity $(\mathrm{RH})(\geq 90 \%)$ without wetness occurred with a frequency of 7.1 and $6.2 \%$, respectively. Accordingly, the effect of interruption of 24-h wetness periods by dry periods of high or low RH on infections caused by Stemphylium vesicarium on pear was determined. Pear plants inoculated with conidia of $S$.

of variable length $(0,3,6,12,18$, or $24 \mathrm{~h})$ and a second wet period of $12 \mathrm{~h}$. The dry period consisted either of low $(60 \%)$ or high (96\%) RH. The infection process was irreversibly stopped under low RH during dry periods between wetness, but continued at high $\mathrm{RH}$. The effect of high $\mathrm{RH}$ on disease severity in the absence of wetness was also determined. Pear plants inoculated with $S$. vesicarium were exposed to periods of variable length ( 3 to $24 \mathrm{~h}$ ) either at high $\mathrm{RH}(96 \%)$ in the presence of wetness or at high RH (96\%) without wetness. No infections were observed on plants incubated under high RH without wetness, indicating that conidia of $S$. vesicarium require the presence of a water film in the plant surface to develop infections on pear.
\end{abstract} vesicarium were exposed to a 12 -h wet period followed by a dry period
Additional keywords: disease forecasting, Pyrus communis.
Brown spot of pear (Pyrus communis L.) is caused by the fungus Stemphylium vesicarium (Wallr.) E. Simmons. Production losses in commercial orchards may be high if weather conditions are favorable for infection. Several fruit-growing areas are affected by this disease in southern Europe, including Catalonia (Spain), Emilia-Romagna (Italy), and Bouches du Rhone (France) (6, 28,31 ), but in recent years, outbreaks have been reported in the Netherlands (B. Heijne, personal communication) and Portugal (A. J. Teixeira, personal communication). Host susceptibility differs among pear cultivars, with Abate Fetel, Passe Crassane, Alexandrine, and Conference being the most susceptible (25).

Wetness and temperature during wetness periods are the main weather variables affecting severity of brown spot of pear $(9,22$, $26,27)$. Wet periods in pear orchards are not always continuous and may be interrupted by short dry periods, especially after rain, and may be followed by dew or rain (22). Also, during wetness interruption, the relative humidity $(\mathrm{RH})$ may be high $(\geq 90 \%)$ or low (60 to $80 \%$ ). However, the effect of intermittent wetness periods and RH during wetness interruptions on the infection process by $S$. vesicarium on pear is unknown.

Another field observation in Girona (Spain) is the presence of relatively long periods of high $\mathrm{RH}$ without dew formation (22). It is not known if high $\mathrm{RH}$ in the absence of wetness can trigger infection of pear by $S$. vesicarium. Previous studies showed that conidia of $S$. vesicarium germinated only when $\mathrm{RH}$ ranged from 98 to $100 \%$ and conidia were exposed to free moisture (27). However, the influence of high $\mathrm{RH}$ on infection of pear by $S$. vesicarium in the absence of wetness has not been investigated.

A forecasting model (BSPcast) that predicts risk of brown spot of pear was developed from controlled environment experiments (26). The model quantifies the effect on the severity of infections of cumulated wetness and temperature during wetness periods

Corresponding author: I. Llorente; E-mail address: llorente@intea.udg.es

Publication no. P-2001-1102-02R

(C) 2002 The American Phytopathological Society within 24-h intervals. BSPcast was evaluated in the field and was validated for scheduling fungicide sprays in experimental and mesoscale field plots in Spain and Italy $(22-24,26)$. The average savings in the number of fungicide sprays using BSPcast were 20 to $70 \%$ compared with the fixed-spray schedule (23). Understanding the influence of interrupted wetness periods and high $\mathrm{RH}$ on disease development in the absence of dew is of great epidemiological interest for management of brown spot of pear and could increase the predictive capacity and accuracy of the BSPcast model.

The objectives of this study were (i) to analyze the pattern and frequency of interruptions of wetness and of periods with high $\mathrm{RH}$ without wetness formation in pear orchards, and (ii) to determine the effect of duration and $\mathrm{RH}$ of dry periods interrupting wetness periods, and of high RH periods without wetness, on brown spot disease of pear caused by $S$. vesicarium.

\section{MATERIALS AND METHODS}

Measurement of wetness, $\mathrm{RH}$, and temperature in pear orchards. Pear orchards were located in Girona Province (Catalonia, Spain). Environmental variables were monitored with CR10 and CR10X dataloggers (Campbell Scientific Ltd., Leicester, UK) connected to combined temperature-RH (Model HMP35AC), wetness (Model 237), and rainfall (Model ARG100) sensors. Wetness sensors provided data on surface wetness in relative units ranging from 0 (dry) to 100 (water film). The wetness sensor essentially measures resistance through an AC Half Bridge. Because we used a noncoated sensor, a sharply defined transition from dry to wet was observed. Readings from 0 (dry) to 100 (wet) were obtained according to the manufacturer's instructions by the offset method. Wetness sensor calibration was performed by means of inducing dew formation into a controlled environment chamber containing the sensor and pear plants (PGR15; Conviron, Winnipeg, Manitoba, Canada). Simultaneous sensor readings and visual observation of sensor and plant leaf surface were done through the window of the controlled environment chamber. Variable amounts of dew were produced by equilibrating the chamber at near saturating $\mathrm{RH}(>96 \%)$ and $25^{\circ} \mathrm{C}$, 
and subsequently selecting given temperatures below $25^{\circ} \mathrm{C}$. In most trials, dew was clearly observed when sensor readings were about 50 units. However, dew was observed, in some cases, when sensor readings were around 25 . A biological threshold at 25 sensorreading units was tested for the effect on disease severity in inoculated plants. Disease was only assessed at a qualitative level due to difficulties to maintain sensor readings at precisely constant values around 25 during several hours. Practically no lesions were observed upon incubation for $24 \mathrm{~h}$ under these conditions.

A field study was performed during years 1993 and 1994 in two orchards including 200 wetness days (data not shown), in order to compare the duration of wetness estimated according to the 25 and 50 thresholds. A significant relationship following the equation $\mathrm{W}_{25}=2.25+0.91 \mathrm{~W}_{50}\left(P<0.0001, R^{2}=0.89\right)$ was obtained, indicating that a mean of $2.25 \mathrm{~h}$ of additional wetness duration was calculated when considering the 25 unit threshold instead of a threshold of 50. In addition, a wet-dry threshold of 50 was used in validation of BSPcast, the warning system for management of brown spot of pear (22-24,26).

Therefore, based on the results obtained in wetness sensor calibration under controlled environment conditions and in the field, a threshold of 50 was selected for the present study.

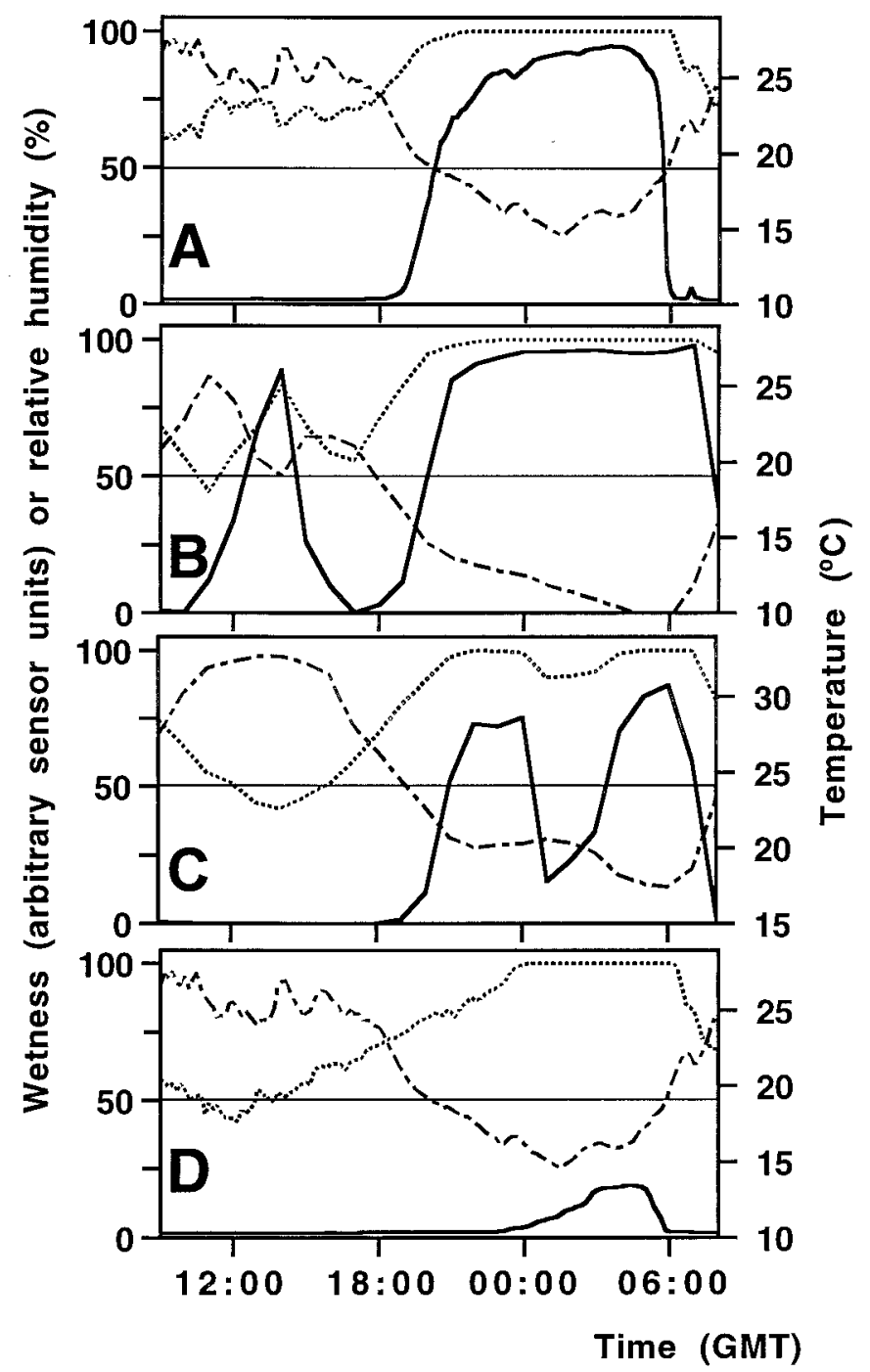

Fig. 1. Typical patterns of the dynamics of wetness (solid line), temperature (dashed line), and relative humidity $(\mathrm{RH})$ (dotted line) in several pear orchards studied in Girona (Spain). A, Wetness due to dew (Cassa orchard, 20 to 21 June 1993); B, interrupted wetness period with low RH $(<90 \%)$ (Perello orchard, 28 to 29 August 1997); C, interrupted wetness period with high RH ( $\geq 90 \%$ ) (Perello orchard, 22 to 23 August 1996); and D, period with high RH but without wetness formation (Cassa orchard, 22 to 23 July 1993).
Two unpainted wetness sensors were placed per orchard. They were positioned in the canopy in suitable sites unobstructed by upper tree leaves to avoid perturbation of dew formation or rain, and were fixed by means of a supporting device at a deployment angle of $0^{\circ}$ with respect to the horizontal line.

In previous observations (data not shown), the duration of wetness period was longer in the upper canopy of the pear trees when wetness was due to dew, and shorter when wetness was due to rain. Because most wetness periods in our orchards are due to dew, the wetness sensors were placed on trees at 1.5 to $1.8 \mathrm{~m}$ above the soil surface in the middle of the orchards.

The wetness sensor orientation with respect to the cardinal points was conditioned by the orchard characteristics, especially by the orientation of the tree rows, but the criterion adopted was to ensure long periods of wetness. Consequently, no sensors were placed in the East orientation to avoid the effect of sunrise, which provokes rapid dew disappearance early in the morning.

The rainfall sensors were placed at the end of a row of trees and were unobstructed to ensure that canopy did not interfere with measurements.

Temperature and RH were measured at 10-min intervals and wetness and rainfall every $20 \mathrm{~s}$ and both measurements were recorded by the datalogger at hourly intervals. Day was a period of $24 \mathrm{~h}$ ranging from 8:00 Greenwich Mean Time (GMT) of previous day to 8:00 GMT of current day to avoid partition of dew periods that in most cases began at nightfall and ended at sunrise. The time between sunset and sunrise did not differ between the study sites, but it did differ in regard to the period studied.

The following pear orchards, periods, and years of study were used for compilation of interrupted wetness and high RH without wetness days: Cassa (29 April to 14 October 1993), Riudellots (16 May to 12 October 1995 and 19 May to 22 October 1996), Perello (1 June to 24 October 1996 and 21 May to 21 September 1997), and Ulla (13 May to 22 July 1999).

Plant material. Two- to three-year-old pear plants of cv. Conference of CAV clone were obtained by micropropagation (Agromillora Catalana S.A., Barcelona, Spain), grown in 0.5-liter plastic containers filled with BVV potting mix (Prodeasa, Girona, Spain), and were used for inoculations with the pathogen. Fertilizer (200 ppm of 20-10-20 N-P-K) was applied every week. Plants were pruned and left in the greenhouse to leave one main shoot, and when the shoot was about 30 to $40 \mathrm{~cm}$ high and had 15 to 20 leaves, they were used for experiments.

Inoculum production. A virulent strain of $S$. vesicarium (EPS26) isolated from infected pear fruit of Girona (Spain) was used for inoculations. Cultures were grown on V8 agar (11) prepared with 1 liter of sterilized water, $100 \mathrm{~g}$ of V8 juice (Campbell, Ltd., Italy), $3 \mathrm{~g}$ of $\mathrm{CaCO}_{3}$, and $20 \mathrm{~g}$ of agar. The $\mathrm{pH}$ was adjusted to 7. Inoculated petri dishes were incubated at $20^{\circ} \mathrm{C}$ with $18 \mathrm{~h}$ fluorescent light and $6 \mathrm{~h}$ darkness. Conidial suspensions containing mature conidia were obtained from cultures flooded with distilled water amended with $0.5 \%$ Tween 20 . The surface of colonies were gently rubbed with a sterile cotton swab and the water/spore mixture was filtered through mesh sieves $(0.2 \mathrm{~mm})$ to separate mycelium from conidia. Conidial concentration was determined with a hemacytometer and adjusted to $2 \times 10^{5} \mathrm{ml}^{-1}$. The conidial suspensions were maintained at $4{ }^{\circ} \mathrm{C}$ to prevent germination during manipulations. Before each experiment and to assess viability, 200 conidia were examined under a microscope after $2 \mathrm{~h}$ of incubation at $20^{\circ} \mathrm{C}$ in the hemacytometer chamber. The beginning of germ tube development was used as germination criteria, and suspensions with less than $90 \%$ germination were discarded. Inoculation was performed within $2 \mathrm{~h}$ after the conidial suspension was obtained.

Inoculation. Leaves were inoculated on both surfaces to run off with a compressed air atomizer operated at $2 \mathrm{kPa}$. Two spray passes were made across each plant, one to wet the adaxial leaf face and another to wet the abaxial face. Noninoculated checks were processed with distilled water amended with $0.5 \%$ Tween 20 . 
Interrupted wetness experiments. After inoculation with the conidial suspension, plants were exposed to either continuous or interrupted wet periods. Treatments consisted of an initial wet period of $12 \mathrm{~h}$, a variable-length dry period $(3,6,12,18$, or $24 \mathrm{~h}$ ), and a final wet period of $12 \mathrm{~h}$. Dry periods consisted of either high $(96 \%)$ or low $(60 \%)$ RH. Treatments consisting of 12- or 24-h wetness without interruption were performed as controls.

Immediately after inoculation, plants were introduced in polyethylene plastic bags with the inside face sprayed with distilled water to ensure high RH and placed for $12 \mathrm{~h}$ in a controlled environment chamber (PGR15; Conviron) maintained at $22.5^{\circ} \mathrm{C}$ in darkness. After the first wetness period, plants were removed from wetness, except those corresponding to $24 \mathrm{~h}$ of continuous wet, and were dried with a fan for $20 \mathrm{~min}$ to remove the surface water film. The remaining plants were kept dry in either high $(96 \%)$ or low $(60 \%) \mathrm{RH}$ for $3,6,12,18$, and $24 \mathrm{~h}$ at $22.5^{\circ} \mathrm{C}$ in darkness. After the appropriate dry period, plants were sprayed until runoff with sterile distilled water and placed again into polyethylene plastic bags with the inside face sprayed with distilled water, and placed in a controlled environment chamber maintained for $12 \mathrm{~h}$ at $22.5^{\circ} \mathrm{C}$ and $96 \% \mathrm{RH}$ in darkness. During the experiments, two controlled environment chambers were used: (i) a high RH chamber at $22.5^{\circ} \mathrm{C}\left( \pm 0.5^{\circ} \mathrm{C}\right)$ and $96 \%( \pm 3 \%) \mathrm{RH}$, and (ii) a homemade low RH chamber with $60 \%( \pm 5 \%) \mathrm{RH}$ controlled by a controller (CD303; Carel, Padova, Italy) and temperature at $22.5^{\circ} \mathrm{C}\left( \pm 1^{\circ} \mathrm{C}\right)$ maintained with a temperature controller (LNS1; Refac, Burgos, Spain). When the exposure to the wet-dry-wet conditions ended, plants were placed in a homemade chamber for the expression of symptoms at $22.5^{\circ} \mathrm{C}, 70 \% \mathrm{RH}$, and a $16 \mathrm{~h}$ light, $8 \mathrm{~h}$ dark photoperiod $\left(180 \mu \mathrm{E} \mathrm{m}^{-2} \mathrm{~s}^{-1}\right)$. To monitor environmental variables continuously within the chambers, we used CR10 dataloggers that were connected to wetness, temperature, and $\mathrm{RH}$ sensors as described previously. To ensure that water did not condense inside the chambers, two unpainted wetness sensors (Model 237) were placed in the middle of plants above the maximum canopy height to prevent sensor obstruction by the vegetation. Temperature and $\mathrm{RH}$ were measured with HMP35AC sensors, which provided a precision on $\mathrm{RH}$ determinations of $\pm 3 \%$ in the range of 90 to $99 \%$ $\mathrm{RH}$ and of $\pm 0.1^{\circ} \mathrm{C}$ for temperature.

The experiment was arranged as a completely randomized design of 12 treatments (length of interrupted wetness period, RH during wetness interruption). Each treatment was composed of three replications of three plants per replication. The experiment was conducted twice.

High RH experiments. Plants were inoculated with conidial suspensions of $S$. vesicarium, dried for $20 \mathrm{~min}$ with a fan, and placed in a growth chamber with high $\mathrm{RH}(96 \%)$ at $22.5^{\circ} \mathrm{C}$. Plants exposed to 12 or $24 \mathrm{~h}$ of continuous wetness were placed in polyethylene plastic bags with the inside face sprayed with distilled water to ensure high RH. Plants were removed at $0,6,12,18,21$, and $24 \mathrm{~h}$, de- pending on the experiment, and placed in a growth chamber for symptom development at $22.5^{\circ} \mathrm{C}, 70 \% \mathrm{RH}$, and a photoperiod of $16 \mathrm{~h}$ light $\left(180 \mu \mathrm{E} \mathrm{m}^{-2} \mathrm{~s}^{-1}\right)$ and $8 \mathrm{~h}$ dark. The environmental variables within the chambers were monitored with a CR10 datalogger connected to two leaf wetness sensors (Model 237) and a HMP35AC sensor for temperature and RH measurements. Each treatment included three plants, and the experiment was conducted three times.

Disease assessment. Disease severity was assessed after 4 to 6 days of incubation in the symptom expression chamber as the mean number of lesions per leaf for each plant. Lesions were counted on 10 leaves located nearest the shoot tip, because these leaves are most susceptible to $S$. vesicarium (25).

Data analysis. The effect on disease severity of the length of the interrupted wetness period and of RH was determined by analysis of variance using the general linear models procedure of SAS (version 8.00, SAS Institute Inc., Cary, NC). All data sets were tested for equality of variance (Bartlett test) and normality (Shapiro-Wilk test). To determine the effect of the length of the interrupted period and RH during this period, two different procedures were used. In the first procedure, data were analyzed, excluding the control treatments corresponding to 12 and $24 \mathrm{~h}$ of continuous wetness. An analysis of covariance was performed with the length of the interrupted period as the covariate and the level of RH (low or high) during the interruption as the classification variable. In the second procedure, the control treatments corresponding to 12 and $24 \mathrm{~h}$ of continuous wetness were compared with all treatments using contrasts, and the classification variables were the level of $\mathrm{RH}$ (low or high) and the length of the interrupted period.

\section{RESULTS}

Analysis of the frequency of days with interrupted wetness and high RH in orchards. In most daily periods studied (84\%), wetness was produced at night because dew was formed when temperature decreased and RH increased, and wetness disappeared rapidly after sunrise as the temperature increased and $\mathrm{RH}$ decreased (Fig. 1A). In some cases, a period of wetness due to rain during the day was followed by a dry period, then by a continuous wetness period at night (Fig. 1B). The wetness period at nighttime was in some occasions interrupted by a dry period (Fig. 1C). Also, there were days without wetness (Fig. 1D). The number of days with interrupted wetness ranged from 4 in Riudellots orchard in 1995 (2.7\% of total days analyzed) to 16 in Perello orchard in 1997 (13\%) (Table 1), and the mean frequency of days with interrupted wetness periods in the pear orchards studied was $7 \%$. In $72 \%$ of these days, the duration of the interrupted wetness period was shorter than $6 \mathrm{~h}$ (Table 1). It was also observed that during the interrupted wetness period, the $\mathrm{RH}$ was lower than $90 \%$ during the entire dry period (Fig. 1B), higher or equal to $90 \%$ during the entire interruption (Fig. 1C), or evenly mixed of high ( $\geq 90 \%)$ and

TABLE 1. Analysis of the frequency of uninterrupted and interrupted wetness days, and of days with high ( $\geq 90 \%)$ relative humidity (RH) without wetness in several pear orchards and years in Girona (Spain)

\begin{tabular}{|c|c|c|c|c|c|c|c|c|c|c|c|c|c|}
\hline \multirow[b]{2}{*}{ Orchard and year } & \multirow{2}{*}{$\begin{array}{l}\text { Total days } \\
\text { analyzed }^{\text {a }}\end{array}$} & \multirow{2}{*}{$\begin{array}{l}\text { Days with } \\
\text { uninterrupted } \\
\text { wetness }\end{array}$} & \multirow{2}{*}{$\begin{array}{c}\text { Days with } \\
\text { interrupted } \\
\text { wetness }\end{array}$} & \multicolumn{3}{|c|}{$\begin{array}{l}\text { Days with interrupted } \\
\text { wetness duration }^{\mathrm{b}} \\
\end{array}$} & \multicolumn{3}{|c|}{$\begin{array}{c}\text { Days with interrupted } \\
\text { wetness having } \mathrm{RH}^{\mathrm{c}}\end{array}$} & \multirow{2}{*}{$\begin{array}{l}\text { Days with RH } \\
\geq 90 \% \text { without } \\
\text { wetness }\end{array}$} & \multicolumn{3}{|c|}{$\begin{array}{c}\text { Days with } \mathrm{RH} \geq 90 \% \\
\text { without wetness of duration } \\
\end{array}$} \\
\hline & & & & $\mathrm{S}$ & $\mathrm{M}$ & $\mathrm{L}$ & $\mathrm{L}$ & $\mathrm{M}$ & $\mathrm{H}$ & & $\mathrm{S}$ & $\mathrm{M}$ & $\mathrm{L}$ \\
\hline Cassa, 1993 & 168 & 146 & 13 & 5 & 4 & 4 & 5 & 5 & 3 & 4 & 1 & 1 & 2 \\
\hline Riudellots, 1996 & 156 & 126 & 10 & 4 & 2 & 4 & 7 & 2 & 1 & 15 & 1 & 1 & 13 \\
\hline Perello, 1996 & 147 & 130 & 10 & 5 & 5 & 6 & 4 & 8 & 4 & 4 & 2 & 2 & - \\
\hline Perello, 1997 & 123 & 102 & 16 & 4 & 4 & 2 & 4 & 2 & 4 & 1 & - & 1 & - \\
\hline
\end{tabular}

${ }^{a}$ A day was considered a period of $24 \mathrm{~h}$ from 8:00 Greenwich Mean Time (GMT) of previous day to 8:00 GMT of the current day.

${ }^{\mathrm{b}} \mathrm{S}=d \leq 3 ; \mathrm{M}=3<d \leq 6 ; \mathrm{L}=d>6(d=$ duration period in hours).

${ }^{\mathrm{c}} \mathrm{L}=\mathrm{RH}$ of $<90 \%$ during entire dry period between wet periods; $\mathrm{H}=\mathrm{RH}$ of $\geq 90 \%$ during the entire interruption period; $\mathrm{M}=1 \mathrm{low}(<90 \%)$ and high $(\geq 90 \%) \mathrm{RH}$ during the interruption period. 
low $(<90 \%) \mathrm{RH}$. The most frequent situation during interrupted wetness periods was low RH (45\% of cases) or mixed RH $(29 \%$ of cases). Only in $26 \%$ of the interrupted wetness periods was RH higher than $90 \%$ (Table 1). In all days with interrupted wetness periods, rain was also observed. Interrupted wetness periods with low RH occurred during the day, whereas interrupted wetness periods with high RH occurred mainly during the night. Periods with mixed conditions occurred mainly at nightfall or sunrise but also during the day.

Days with high RH ( $\geq 90 \%)$ but no wetness (Fig. 1D) were infrequent in most orchards $(<3.1 \%$ of days). However, Riudellots orchard showed 15 days of this pattern $(9.6 \%)$ in 1995 and 26 days in $1996(17.4 \%)$ (Table 1). The length of these periods with high $\mathrm{RH}$ and absence of wetness was longer than $6 \mathrm{~h}$ in $74 \%$ of cases and shorter than $6 \mathrm{~h}$ in $26 \%$ of cases. Only in one orchard (Riudellots in 1995 and 1996) were these periods sometimes $>12 \mathrm{~h}$.

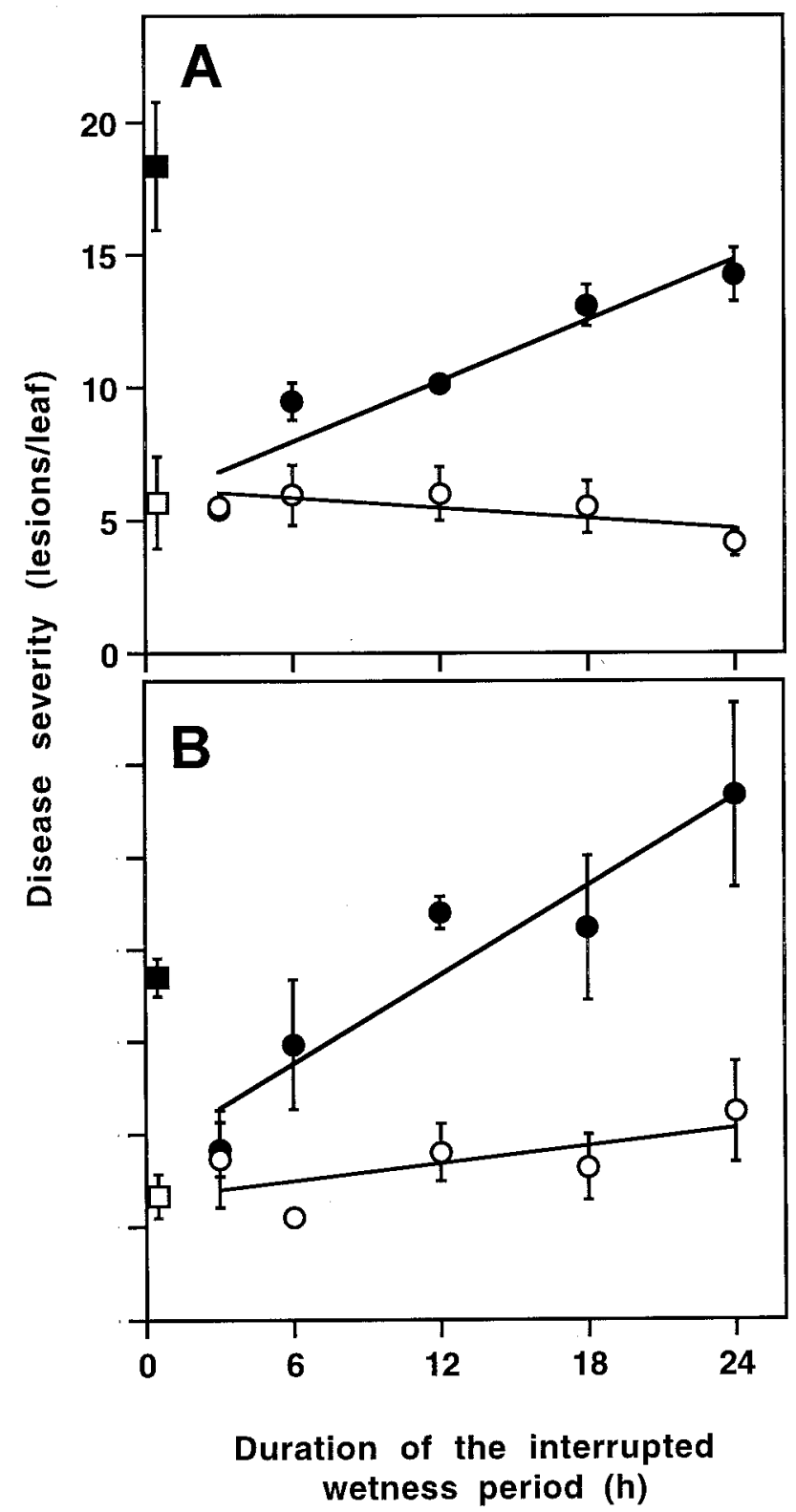

Fig. 2. Effect of the length and relative humidity $(\mathrm{RH})$ during the interruption of wetness period on severity of brown spot of pear caused by Stemphylium vesicarium. The treatments consisted of an initial wet period of $12 \mathrm{~h}$ followed by an interrupted period of variable length with different levels of $\mathrm{RH}(\mathrm{O}=60 \% ;-=96 \%)$ and a final wet period of $12 \mathrm{~h}$. Controls of $12 \mathrm{~h}(\square)$ and $24 \mathrm{~h}(\mathbf{\square})$ of continuous wetness are also presented. Disease severity values correspond to the mean of three replicates. Bars represent the standard error of the mean. A, Run 1; B, Run 2.
Effect of interrupted wetness on disease severity. We observed differences in plant susceptibility to infection between trials. During the second trial, disease severity was about onethird that in the first trial. However, this difference did not affect the consistency of results.

The effect of the length of the dry period during the interruption of wetness, preceded and followed by a 12-h wet period, depended on the RH (Fig. 2). When RH was low during the interrupted wetness period, no significant changes in disease severity were observed upon increase in the duration of the interruption period. By contrast, at high $\mathrm{RH}$, disease severity increased with the duration of the interruption period. The slope of the regression line was significantly lower at low RH than at high RH during the interruption period in the two experiments $(P=0.0014$ and 0.0062$)$.

Data were analyzed by comparison of the two controls (12 and $24 \mathrm{~h}$ of continuous wetness) with the remaining treatments. Significant differences in disease severity were observed between the $24 \mathrm{~h}$ continuous wetness control and treatments at low RH during interruption of the wetness period in the two experiments $(P=$ 0.0001 and 0.0015). However, when the same treatments were compared with the $12 \mathrm{~h}$ continuous wetness control, no significant differences were observed for the two experiments $(P=0.8941$ and 0.5173 ).

When the comparisons were performed between the $24 \mathrm{~h}$ continuous wetness control and treatments at high RH the significance of the differences depended on the experiment. In experiment 1 , differences were significant $(P=0.0003)$, but in experiment 2 , they were not significant $(P=0.8315)$. Signifi-cant differences in disease severity for the two experiments were observed between treatments consisting of interruptions at high $\mathrm{RH}$ and the $12 \mathrm{~h}$ continuous wetness control $(P=0.0181$ and 0.0002$)$.

Effect of high RH on disease severity. In the absence of wetness under high $\mathrm{RH}$, disease was not observed on most plants at exposure times of $0,6,12$, and $18 \mathrm{~h}$, but very low disease severity levels were observed in plants incubated at 21 and $24 \mathrm{~h}$ in two of three experiments (Fig. 3). By contrast, disease severity was high and increased with the exposure time to high $\mathrm{RH}$ in the presence of wetness.

\section{DISCUSSION}

Studies of the influence of wetness on fungal diseases of plants generally are conducted under continuous wetness in controlled environment experiments, but these conditions may not reflect situations observed in the field. In a previous study, we showed that the distribution of duration of wetness periods in orchards of Catalonia (Spain) and Emilia-Romagna (Italy) ranged from 1 to $24 \mathrm{~h}$ but in most cases was between 8 and $10 \mathrm{~h}$ (23). However, the dynamics of wetness is sometimes characterized by short interruptions consisting of dry periods of high or low $\mathrm{RH}$, or even by high $\mathrm{RH}$ periods without wetness, which can affect significantly the infection process, by fungal plant pathogens $(1,3,5,8,10,14,29,30)$. In the present study, of 813 days analyzed in four orchards and 5 years, 682 corresponded to daily continuous wetness, 58 presented interrupted wetness periods, and 50 showed high RH without wetness. The patterns and frequency of wetness interruptions and high $\mathrm{RH}$ without wetness periods may be common to other pear production areas in the world. However, the patterns may be affected by the type of sensor used $(12,13,18)$ or other sensor characteristics such as the coating with paint (21), the orientation and location with respect to the vegetation $(16,21)$, or the deployment position $(7,17)$.

According to our results, surface wetness interruptions and high RH without wetness are relatively important in some orchards and years. Both situations may have a significant influence in disease development and in the accuracy of disease warning systems such as BSPcast for management of brown spot of pear $(22-24,26)$, because BSPcast considers all daily wetness periods continuous. It is also important to know the effect of periods with high RH and 
no wetness, because these periods are not considered in BSPcast and may be conducive to infections by $S$. vesicarium.

Among fungal plant pathogens, the effect of wetness interruption depends on the RH during interruption and on the pathosystem. In many cases, wetness interruptions affect the infection process negatively. The severity of leaf and fruit spots caused by Botryosphaeria obtusa in apple did not increase, and short germ tubes stopped growth when wetness was interrupted, regardless of whether RH was high or low during the interrupted period (3). Conidia of Botrytis cinerea, Cercospora musae, and Monilia fructicola did not survive an interrupted wetness period with low RH when the germ tubes were long but survived when the germ tubes were short (15). The severity of infections of Coccomyces hiemalis in sour cherry (14), Alternaria porri f. sp. solani and Phytophthora infestans in potato, and Uromyces phaseoli in bean (4) did not increase significantly under low RH during the interrupted period. In contrast to these fungal plant pathogens, germ tubes survive low RH conditions between wet periods in fungi adapted to semiarid habitats, such as $S$. botryosum $\mathrm{f}$. sp. lycopersici on tomato (4), or to tropical humid climates, such as Mycosphaerella fijiensis on banana (19). Our results showed clearly that low RH during periods of interruption of wetness stops the infection process in $S$. vesicarium. A dry period of $3 \mathrm{~h}$ at low $\mathrm{RH}$ was enough to prevent subsequent new infections during a 12-h rewetting period. In contrast, high $\mathrm{RH}$ during the intervening dry period slowed infections at short durations but increased infections with the increase in length of the wetness period interruption. This result suggests that germ tubes of $S$. vesicarium are highly susceptible to drying conditions if they have not penetrated plant tissues.

In $S$. vesicarium, the effect of interruption of wetness at high $\mathrm{RH}$ depends on the duration of the interruption, which was in agreement with studies performed with Cercospora kikuchii in soybean (29) and Mycosphaerella graminicola on wheat (30). High RH during the interruption of wetness may enable conidia of $S$. vesicarium to continue germ tube development, but periods of high $\mathrm{RH}>3 \mathrm{~h}$ are required to resume germ tube growth again after wetness interruption. In our study, it was not clear whether high $\mathrm{RH}$ during interruption of the wetness period for $>3$ to $6 \mathrm{~h}$ contributed only to increase the survival of germ tubes without significant elongation or permitted germ tube elongation and penetration, but both processes could increase disease severity during the subsequent wet period. However, histopathological studies are needed to fully understand the mechanism of spore germination and tissue penetration by germinating conidia of $S$. vesicarium under low or high RH during interrupted wetness periods.

Our finding that brown spot of pear did not occur under high $\mathrm{RH}$ in the absence of wetness is in agreement with a previous observation that conidia of $S$. vesicarium germinate at high RH only when a water film is present (27). In other studies, germination of conidia of several fungi was reported at high $\mathrm{RH}$, but no information about the presence or absence of wetness during these experiments was given (20). Also, spores of certain fungal plant pathogens can germinate at low $\mathrm{RH}$, which has been related to a high osmotic pressure of the spores and a capacity to absorb water from air (2). Experiments to determine the effect of high RH in the absence of wetness must be conducted with very precise control of temperature and $\mathrm{RH}$, because a slight decrease in temperature will cool air below the dew point with a consequent condensation of water on the plant surface (20). In our experiments, water condensation on leaves was not observed, thus demonstrating that conidia of $S$. vesicarium cannot infect at high $\mathrm{RH}$ in the absence of wetness. However, the sensors used in our study did not reflect particular conditions of wetness in microsites on leaves, which can lead to water condensation that might be available to individual spores. This may explain the fact that even in the absence of wetness according to sensor readings, a few infections occurred.

Aerial fungal plant pathogens may counteract with success fluctuating wet-dry-wet conditions in the field, depending on their specific germination rate of conidia and survival capacity and penetration rate of germ tubes into the plant tissues. Carisse and Kushalappa (8) suggested that rapidity in one of these factors (e.g., penetration rate) can compensate for deficiencies in other traits (e.g., survival in dryness). An interesting example is $S$. botryosum $\mathrm{f}$. $\mathrm{sp}$. lycopersici, which requires long wetting periods to germinate and penetrate but whose germinating spores can survive dry periods. By contrast, the sporangia of Phytophthora infestans have poor tolerance to dry conditions, but the pathogen succeeds in semiarid climate as a result of rapid germination rate of spores and high penetration rate of germ tubes. Some pathogens, such as A. porri f. sp. solani, may exhibit a high survival of germinating spores to dryness and rapid germination rate (4). The germination rate of conidia of $S$. vesicarium is very high in comparison with other fungi, because under wet conditions, $50 \%$ of conidia germi-

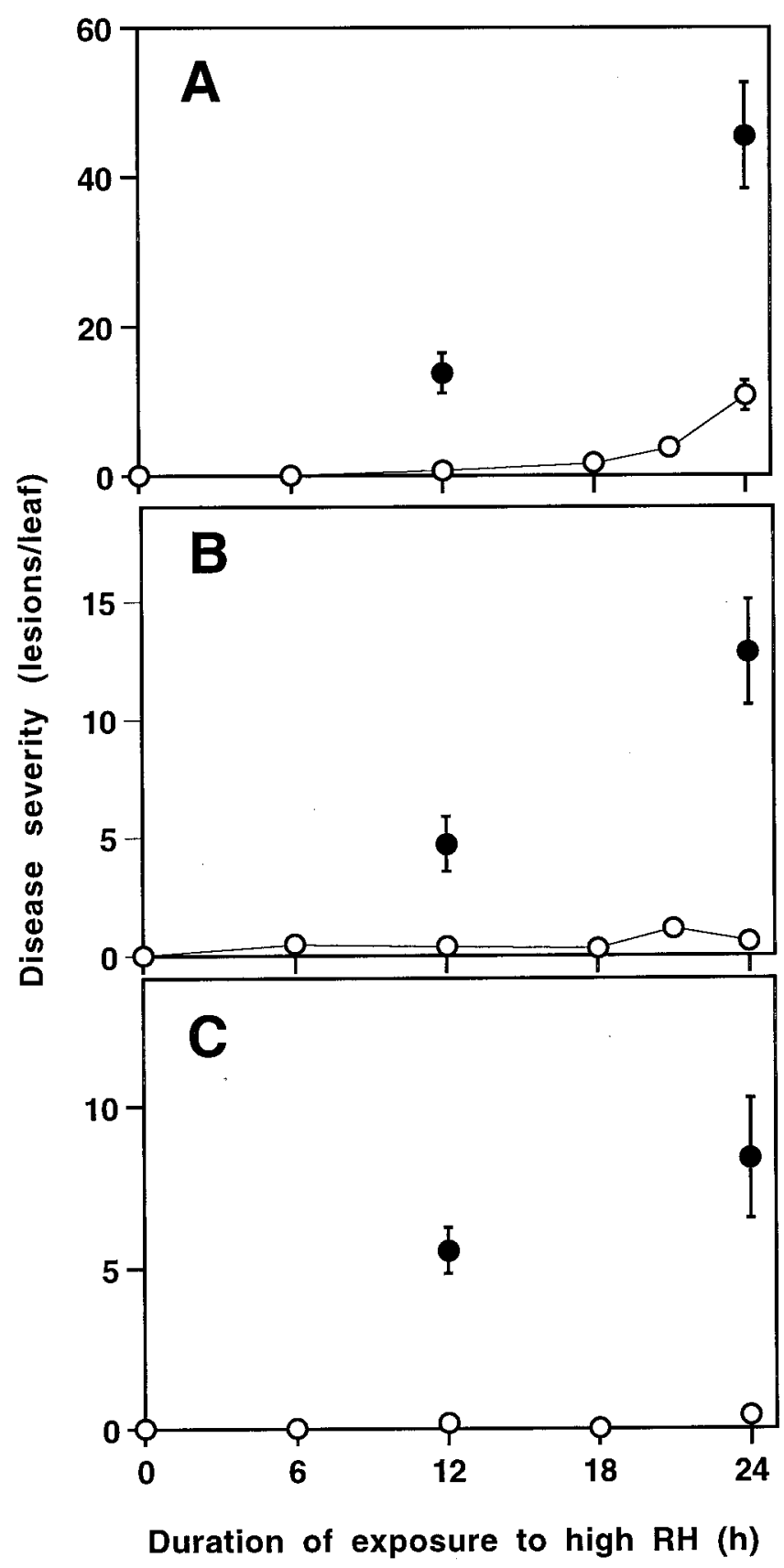

Fig. 3. Effect of the length of the exposure to high relative humidity (RH) (96\%) on severity of brown spot of pear caused by Stemphylium vesicarium depending on the presence $(\bullet)$ or absence $(O)$ of wetness. Disease severity values correspond to the mean of three replicates. Bars represent the standard error of the mean. A, Run 1; B, Run 2; and $\mathbf{C}$, Run 3. 
nate in $<1 \mathrm{~h}$ at optimal temperature $(9,27)$. However, the results presented here indicate that germinated conidia of $S$. vesicarium cannot survive dry periods of $\geq 3 \mathrm{~h}$ at low $\mathrm{RH}$ and cannot infect pear under high RH in the absence of wetness. Therefore, S. vesicarium is characterized by a high germination rate but a low survival capacity of germinated conidia.

The design of experiments concerning the effect of interrupted wetness on disease severity used in our study may have a limitation because the starting and ending wetness periods were fixed at $12 \mathrm{~h}$ and the length of the intervening dry periods corresponding to wetness interruptions varied from 0 to $24 \mathrm{~h}$. Consequently, the total incubation length varied from $24 \mathrm{~h}$ ( $0 \mathrm{~h}$ of dry period) to $48 \mathrm{~h}$ ( $24 \mathrm{~h}$ of dry period). This variation in duration of the incubation period might distort comparisons of disease severity, especially when dry periods were long and $\mathrm{RH}$ was high. In contrast, this design permitted the comparison between continuous wetness ( $24 \mathrm{~h}$ ) and other treatments with the same total wetness duration. A control treatment with $48 \mathrm{~h}$ of continuous wetness would have permitted the comparison with the treatment corresponding to $24 \mathrm{~h}$ of interruption ( $48 \mathrm{~h}$ of total incubation), but unfortunately it was not included in the experiment. An alternative experimental design with the total incubation length equal for all treatments was not tested and would implicate a variation in the length of the second wetness period, thus, making the total wetness period different among treatments. However, in this design, no comparisons between interrupted periods with the same total wetness duration can be done among treatments. Additionally, the effect of the length of dry period and of the total wetness period in disease severity might be confounded.

The BSPcast model was validated by an algorithm that computes the accumulated hours of wetness during 24-h intervals, and does not take into account either the effect of interruptions of wetness or the high RH without wetness $(22-24,26)$. We have shown that in the studied area $13.3 \%$ of days corresponded to interrupted wetness or high RH daily periods. Prior to this study, there was doubt about the accuracy of predictions of the BSPcast model under these conditions. However, our experiments demonstrated in only $3.2 \%$ days, corresponding to days with $\mathrm{RH}$ of $<90 \%$ during wetness interruption, it will be necessary to introduce modifications on the model calculations.

The conclusions concerning the model derived from our results are that no modifications of the model predictions are necessary if $\mathrm{RH}$ during wetness interruptions is high $(\geq 96 \%)$, wetness periods should be considered interrupted if the length of the interruption is $\geq 3 \mathrm{~h}$ at low $\mathrm{RH}$, and high $\mathrm{RH}$ periods in the absence of wetness do not constitute conditions for triggering an infection alert. These considerations will be introduced in a new version of the BSPcast model with the aim of improving its performance, and this new version will be evaluated in future field tests.

\section{ACKNOWLEDGMENTS}

This research was supported in part by grants from Instituto Nacional de Investigaciones Agrarias and Subdirección General de Cooperación Internacional of Spain, and Comissió Interdepartamental de Recerca i Tecnologia of the Generalitat de Catalunya. We thank J. Pereda for skillful greenhouse assistance.

\section{LITERATURE CITED}

1. Alderman, S. C., Lacy, M. L., and Everts, K. L. 1985. Influence of interruptions of dew period on numbers of lesions produced on onion by Botrytis squamosa. Phytopathology 75:808-810.

2. Arauz, L. F., and Sutton, T. B. 1989. Influence of temperature and moisture on germination of ascospores and conidia of Botryosphaeria obtusa. Phytopathology 79:667-674.

3. Arauz, L. F., and Sutton, T. B. 1990. Effect of interrupted wetness periods on spore germination and apple infection by Botryosphaeria $o b$ tusa. Phytopathology 80:1218-1220.

4. Bashi, E., and Rotem, J. 1974. Adaptation of four pathogens to semi-arid habitats as conditioned by penetration rate and germination spore survival. Phytopathology 64:1035-1039.

5. Becker, C. M., and Burr, T. J. 1994. Discontinuous wetting and survival of conidia of Venturia inaequalis on apple leaves. Phytopathology 84:372-378.

6. Blancard, D., Allard, E., and Brest, P. 1989. La Stemphyliose du poirier ou "macules brunes." Phytoma 406:37-38.

7. Caprara, C., and Veronesi, G. 1992. La misura dei parametri meteoclimatici in fitoiatria: La bagnatura fogliare. Inform. Fitopatol. 4:29-32.

8. Carisse, O., and Kushalappa, A. C. 1992. Influence of interrupted wet periods, relative humidity, and temperature on infection of carrots by Cercospora carotae. Phytopathology 82:602-606.

9. Cugier, J. P., and Humbert, W. 1991. Stemphyliose du poirier. Etude de la biologie du parasite et recherches des fongicides actifs. Phytoma 431: 47-50.

10. De Vallavieille-Pope, C., Huber, L., Leconte, M., and Goyeau, H. 1995. Comparative effect of temperature and interrupted wet periods on germination, penetration, and infection of Puccinia recondita $\mathrm{f}$. sp. tritici and P. striiformis on wheat seedlings. Phytopathology 85:409-415.

11. Dhingra, O. D., and Sinclair, J. B. 1985. Basic Plant Pathology Methods. CRC Press, Florida.

12. Egger, E., and Marinelli, E. 1995. Confronto tra diversi sensori ed un metodo per la stima della bagnatura fogliare. Inform. Fitopatol. 11:48-54.

13. Egger, E., Marinelli, E., and D'arcangelo, M. 1996. Influenza di diversi metodi per la stima della bagnatura fogliare sulla previsione degli attachi di peronospora e muffa grigia su vite. Inform. Fitopatol. 3:57-61.

14. Eisensmith, S. P., Jones, A. L., and Cress, C. E. 1982. Effects of interrupted wet periods on infections of sour cherry by Coccomyces hiemalis. Phytopathology 72:680-682.

15. Good, H. M., and Zathureczky, P. G. 1967. Effects of drying on the viability of germinated spores of Botrytis cinerea, Cercospora musae, and Monilinia fructicola. Phytopathology 57:719-722.

16. Gozzini, B., Orlandini, S., and Seghi, L. 1996. Influenza della vegetazione e dell'orientamento del sensore sulla rilevazione della bagnatura fogliare. Inform. Fitopatol. 4:55-58.

17. Huber, L., and Gillispie, T. J. 1992. Modeling leaf wetness in relation to plant disease epidemiology. Annu. Rev. Phytopathol. 30:553-577.

18. Huber, L., and Wehrlen, J. M. 1988. La durée d'humectation en protection des plantes: Mesure et modélisation. Déf. Vég. 252:3-11.

19. Jacome, L. H., and Schuh, W. 1992. Effects of leaf wetness duration and temperature on development of Black Sigatoka disease on banana infected by Mycosphaerella fijiensis var. difformis. Phytopathology 82:515-520.

20. Lacy, M. L. 1994. Influence of wetness periods on infection of celery by Septoria apiicola and use in timing sprays for control. Plant Dis. 78:975-979.

21. Lau, Y. F., Gleason, M. L., Zriba, N., Taylor, S. E., and Hinz, P. N. 2000. Effects of coating, deployment angle, and compass orientation on performance of electronic wetness sensors during dew periods. Plant Dis. 84:192-197.

22. Llorente, I. 1997. Development of an infection forecasting model for Stemphylium vesicarium. Evaluation, validation and implementation on experimental plots in commercial pear orchards. Ph.D. thesis. University of Girona, Girona.

23. Llorente, I., Vilardell, P., Bugiani, R., Gherardi, I., and Montesinos, E. 2000. Evaluation of BSPcast disease warning system in reduced fungicide use programs for management of brown spot of pear. Plant Dis. 84:631-637.

24. Montesinos, E., Llorente, I., Moragrega, C., Bonaterra, A., Cervantes, J., and Vilardell, P. 1996. Desarrollo y evaluación a escala productiva de un sistema de control racional de la estemfiliosis (Stemphylium vesicarium) del peral. Fruticul. Prof. 78:96-104.

25. Montesinos, E., Moragrega, C., Llorente, I., and Vilardell, P. 1995. Susceptibility of selected European pear cultivars to infection by Stemphylium vesicarium and influence of leaf and fruit age. Plant Dis. 79:471-473.

26. Montesinos, E., Moragrega, C., Llorente, I., Vilardell, P., Bonaterra, A., Ponti, I., Bugiani, R., Cavani, P., and Brunelli, A. 1995. Development and evaluation of an infection model for Stemphylium vesicarium on pear based on temperature and wetness duration. Phytopathology 85:586-592.

27. Montesinos, E., and Vilardell, P. 1992. Evaluation of FAST as a forecasting system for scheduling fungicide sprays for control of Stemphylium vesicarium on pear. Plant Dis. 76:1221-1226.

28. Ponti, I., Cavanni, P., and Brunelli, A. 1982. "Maculatura bruna" delle pere: Eziologia e difesa. Inform. Fitopatol. 3:35-40.

29. Schuh, W. 1993. Influence of interrupted dew periods, relative humidity, and light on disease severity and latent infections caused by Cercospora kikuchii on soybean. Phytopathology 83:109-113.

30. Shaw, M. W. 1991. Interacting effects of interrupted humid periods and light on infection of wheat leaves by Mycosphaerella graminicola (Septoria tritici). Plant Pathol. 40:595-607.

31. Vilardell, P. 1988. Stemphylium vesicarium en plantaciones de peral. Fruticul. Prof. 18:51-55. 